\title{
Concretização dos princípios constitucionais da administração pública no exercício do serviço público
}

The constitutional principles of public administration concretion in the exercise of public service

La concreción de los principios constitucionales de la administración pública en el ejercicio del servicio público

\section{Resumo}

Constitui-se como a adequada prestação do serviço público - realização dos princípios constitucionais expressos no caput do art. 37 da CF/88 nessa atividade - aquela realizada conforme os valores exarados pelos direitos fundamentais do cidadão. A ideia de serviço público não é estática, sofre constantes variações em função de inúmeros fatores, tais como o momento histórico e o lugar em que é prestada determinada atividade que demonstre a existência de funcionalidade à coletividade, justificando sua execução pelo Estado, de forma direta ou indireta. Assim, pretende-se, neste artigo, apresentar os princípios constitucionais da administração pública, a partir da concretização desses no exercício da prestação do serviço público, direta ou indiretamente, por parte do Estado e seus delegatários.

Palavras-chave: Administração Pública. Serviço Público. Princípios.

\section{Serviço Público}

Conforme dispõe o caput do art. 175, da Constituição Federal (CF): "Incumbe ao Poder Público, na forma da lei, diretamente ou sob regime de concessão ou permissão, sempre através de licitação, a prestação de serviços públicos". A ideia de serviço público não é estática, sofre constantes variações em função de inúmeros fatores, tais como o momento histórico e o lugar em que é prestada determinada atividade que demonstre a existência de funcionabilidade à coletividade, justificando sua execução pelo Estado, de forma direta ou indireta.

Professor (Mestrado e Graduação) da Faculdade de Direito da Universidade de Passo Fundo. E-mail: phillipfranca@hotmail.com.

Recebido em 17/11/2014 - Aprovado em 25/03/2015 http://dx.doi.org/10.5335/hdtv.15n.1.5280 
O conceito de serviço público adotado neste texto, feito com auxílio do magistério de Juarez Freitas (2004), é o seguinte: conjunto de atividades essenciais, assim consideradas pelo ordenamento jurídico, prestadas diretamente pelo Poder Público ou mediante delegação executória lato sensu, tendo em vista atender ao interesse geral e sob a regência dos princípios constitucionais de direito administrativo.

Jacques Chevallier lembra que a noção atual de serviço público

[...] evoca uma realidade mais simples e corriqueira, a saber, a existência em todas as sociedades de um conjunto de atividades consideradas como sendo de interesse comum e devendo ser, a esse título, assumidas pela coletividade, ou seja, por uma esfera de funções coletivas (CHEVALLIER, 2008, p. 146).

O autor assevera, ainda, a possibilidade de variações na concepção dessa ideia. Para ele, essa esfera é indispensável à Constituição e à sobrevivência dos grupos sociais.

Conforme Chevallier (2008, p. 182),

[...] a definição funcional de um serviço público de limites contingentes e a diversidade dos operadores encarregados de concorrer à sua execução demonstram a modificação dos termos da relação com o ambiente social. A visão de um serviço público concebido como um universo à parte, separado do resto da sociedade, quiçá erigido em bastão inatingível, sobreviveu; se ele continua investido de missões específicas, essas não são mais capazes de dotá-lo de um estatuto privilegiado, mas lhe impõem zelar pela qualidade de seu desempenho.

Prosper Weil (1977, p. 81-82) afirma que
[...] elaborada pela doutrina e jurisprudência clássicas, a noção de serviço público comportava ao mesmo tempo um sentido material (atividade de interesse geral) e um sentido orgânico (tomada de cargo pelos poderes públicos): mais exatamente, a separação então feita entre as atividades privadas, prosseguidas com um fim pesso$\mathrm{al}$, e as atividades públicas, exercidas com um fim de interesse geral, estabelecia uma perfeita concordância entre a concepção material e a concepção orgânica do serviço público; ao sublinhar o caráter de serviço público de uma determinada atividade, daí se concluía pela tomada desta atividade a cargo das autoridades administrativas.

A partir do momento em que se admitiu que os particulares podiam ser chamados a colaborar em tarefas de interesse geral, a noção material de serviço iria triunfar e o serviço público tenderia a tornar-se sinônimo de atividade de interesse geral. Ora, se é fácil reconhecer um serviço público em sentido orgânico, nada é mais difícil do que definir um serviço público no sentido material do termo. Por si só, o fim de interesse geral que parece caracterizá-lo é demasiado fluído e incerto, porque ao fim e ao cabo quase todas as atividades humanas concorrem de uma maneira ou de outra para o interesse geral. Se se quer conservar na noção de serviço público um interesse jurídico quer dizer, se se lhe quer ligar determinadas conseqüências jurídicas - é pois preciso acrescentar algo à noção de interesse geral, que constitui sem dúvida um elemento necessário à noção de serviço público, mas não pode constituir um elemento suficiente dela (grifo nosso).

De acordo com Dinora A. M. Grotti (2003), a expressão surgiu pela primeira vez nos textos constitucionais pátrios com a Carta de 1934, não tendo sido, desde então, erigido algum conceito constitucional de serviço público. O texto de 1988 fornece alguns parâmetros, alguns referenciais con- 
formadores da área definida como própria dos serviços públicos. Leciona a autora, ainda, que na Constituição Federal atual dois critérios são frequentemente atribuíveis a tal expressão: o sentido orgânico ou subjetivo, como significado de aparato administrativo do Estado (arts. 37, XIII; 39, § 7º, 40, III, 40, $\S 16 ; 136, \S 1^{\circ}$, II; ADCT art. $2^{\circ}, \S 1^{\circ}$; art. $8^{\circ}$, $\S 4$; 19 e 53), e o objetivo, significando uma modalidade de atividade de natureza pública (arts. 21, X, XI, XII, XIV; 30, V; 37, § 6 ${ }^{\circ} ; 54$, I, 'a'; 61, § 12, II, 'b'; 139, VI; 145, II; 175; 198; 202, § 5。; 223; 241; ADCT art. 66).

Assim, para a autora,

[...] a amostra é bem expressiva de que a Constituição brasileira acolhe a categoria de serviço público, e de que inspira a atuação do Poder Público também na idéia de prestação de um sistema de serviços. Trata-se de atividades de titularidade do Poder Público, que não se desnaturam quando sua execução é delegada a particulares, pois a Constituição fixa um vínculo orgânico com a Administração, ao dispor, no caput do art. 175, que incumbe ao Poder Público a prestação de serviços públicos, diretamente ou sob regime de concessão ou permissão. A Constituição não trata, porém, todos os serviços de maneira uniforme. Os objetivos visados são diferentes; a competência para prestação, bem como as formas de organização e de gestão são distintas; a natureza jurídica da remuneração paga pelos usuários de serviços públicos prestados uti singuli varia; a aplicação dos princípios de direito público especialmente reportados aos serviços com diferente intensidade; há submissão, em graus variáveis, a um regime de direito público e, em algumas situações, ao direto privado. Não há, enfim, um tratamento jurídico uniforme em relação a todos eles. Existem regras constitucionais específicas acerca de questões peculiares (GROTTI, 2003, p. 89).

\section{Atividade pública}

Basicamente, a atividade pública caracteriza-se como a atividade que demonstra a existência de funcionabilidade à coletividade, justificando sua execução pelo Estado, de forma direta ou indireta. O que se observa, então, é que o instituto jurídico serviço público é determinável no sentir da sua aplicação concreta, quando e onde se fizer necessária pontuada atividade do Estado em prol do desenvolvimento da sociedade. Extrai-se, assim, do entendimento de atividades públicas desenvolvidas para a promoção individual e intersubjetiva do cidadão, o rótulo de serviço público, o qual, em razão da assunção estatal de não entendimento adequado desse mister, encontra-se, nos dias de hoje, delegado às concessionárias de serviço público - por intermédio de contratos de concessão.

\section{Concessão}
Segundo Angela Cassia Costaldello (2004, p. 313),
[...] no processo de redimensionamento do Estado e da correspondente atuação da Administração Pública, insere-se a figura do particular e da sua efetiva participação nos "egócios" públicos - com maior con- tundência e consistência - atendendo ao interesse público e, ao contempo, preser- vando um de seus objetivos, que é o de- sempenho da atividade lucrativa.

Entende-se como concessão de serviços públicos o meio jurídico utilizado para que o Estado congregue os seus interesses voltados ao bem comum, com o potencial 
produtivo da iniciativa privada, em que se pode encontrar um pesado investimento concentrado em determinado setor econômico, para o alcance dos objetivos estabelecidos na Constituição, com destaque àqueles indicados em seu art. $3^{\circ}$.

Além de seu respectivo fundamento constitucional - arts. 21, XI e XII; 25, § 2 $2^{\circ}, 175$ e 223 -, expressa o art. $2^{\circ}$, II, da Lei 8.987/95 que a concessão de serviço público é a delegação de sua prestação, feita pelo poder concedente, mediante licitação, na modalidade concorrência, à pessoa jurídica ou consórcio de empresas que demonstre capacidade para seu desempenho, por sua conta e risco e por prazo determinado.

Para Maria Sylvia Zanella Di Pietro (2010) concessão é “o contrato administrativo pelo qual a Administração confere ao particular a execução remunerada de serviço público ou de obra pública, ou lhe cede o uso de bem público, para que explore por sua conta e risco, pelo prazo e nas condições regulamentares e contratuais".

Jean Rivero (1981, p. 515) assevera que a concessão de serviço público:

[...] é um modo de gestão de um serviço em que uma pessoa pública, o concedente, encarrega por um contrato uma pessoa privada, o concessionário, de fazer funcionar o serviço durante um certo tempo, assumindo os seus encargos, mediante o direito de ser remunerado através de prestações dos utentes.

Ainda sobre o instituto, Carmen Lúcia Antunes Rocha (1996, p. 84-85) ensina que:
[...] os princípios que fundamentam o instituto da concessão do serviço público são desdobramentos necessários dos princípios constitucionais da Administração Pública Democrática Republicana, constituída pela Lei Fundamental do Brasil de 1988 (arts. $1^{\circ}, 3^{\circ}, \mathrm{I}, 5^{\circ}$ e 37 ), e dos princípios constitucionais específicos da ordem econômica que se combinam para o perfeito contingenciamento da própria definição jurídica do serviço público (arts. 170, IV e $\mathrm{V}$, e 173, caput). Dos princípios fundamentais positivados na Constituição brasileira, a saber, (a) da juridicidade (Estado de Direito, art. $1^{\circ}$, caput); (b) da democrática participação popular (Estado Democrático, art. $1 .^{\circ}$ e seu parágrafo único); (c) da moralidade pública (arts. $3^{\circ}, \mathrm{I}$, e $37, \mathrm{ca}$ put); (d) da igualdade jurídica (arts. $5^{\circ}$ e 37, caput); (e) da República (arts. $1^{\circ}$ e 37); (f) da responsabilidade pública (arts. $1^{\circ} \mathrm{e}$ $37, \S 6^{\circ}$ ); (g) da livre concorrência (arts. $1^{\circ}$, IV, 170, IV, e 173, caput); e (h) da defesa do consumidor (art. 170, V), decorrem os princípios constitucionais das concessões, que podem ser realçados nos seguintes (e se cuida, observe-se, de acentuação de alguns, não do exaurimento de todos os que subordinam o instituto): (a) exclusividade da competência pública (art. 175, caput, da Constituição da República); (b) participação democrática dos usuários (art. 175, parágrafo único, II); (c) adequação do serviço aos fins e aos interesses da sociedade (art. 175, parágrafo único, IV); (d) tarifa política (art. 175, parágrafo único, III).

\section{Concessionária}

Uma vez bem definida a ideia de concessão, tem-se, de forma simples, que concessionária é aquela empresa a que foi outorgada a concessão. Como visto, este personagem do contexto acordado é figura-chave da nova concepção de relação dos protagonistas da 
interação prática sugerida, quais sejam: a turbulenta relação entre o Estado, a empresa concessionária e o cidadão.

Conforme Hector Jorge Escola 1977/1979), o concessionário gera a prestação do serviço, enquanto a Administração o controla, configurando-se uma verdadeira polícia de serviço, que implica um contínuo e ininterrupto controle de inspeção e intervenção, que se manifesta de diferentes maneiras, como ordens, atos de disposição, organização, direção e planejamento do serviço público, exame dos documentos e livros do concessionário, a fim de comprovar os resultados econômicos de sua exploração, vigilância da prestação material do serviço, fiscalização de certas operações financeiras que pretenda efetuar o concessionário, etc. (DI PIETRO, 2008).

Com fulcro no magistério do mesmo autor, os poderes de fiscalização, direção e controle podem abranger quatro aspectos:

a) o material, referente à execução da atividade objeto do contrato;

b) o técnico, referente à observância dos requisitos estabelecidos nos planos, especificações, regulamentos, cláusulas contratuais;

c) o financeiro, indispensável para a fixação das tarifas e a verificação do equilíbrio econômico-financeiro;

d) o legal, que diz respeito à observância das normas legais e regulamentares.

Hector Jorge Escola (1977/1979), quando trata da possibilidade de o concessionário opor-se à fiscalização indevida do poder concedente assevera que não é admissível que, sob a cor dessa direção e controle, me- diante um desmedido e desnecessário exercício dessa prerrogativa, o concessionário fique excluído dos poderes de iniciativa que lhe devem corresponder, já que o serviço é prestado por sua conta e risco, o que transformaria o concessionário em um mero executor dos desígnios da administração e a concessão em uma forma de execução direta dissimulada. A concessão, então, deixaria de ser tal e ter-se-ia desnaturado, como ocorreria caso se pretendesse submeter todo o agir do concessionário à prévia autorização do concedente ou do órgão encarregado do controle do serviço.

Esse relacionamento não encontrará como último capítulo a questão da privatização de serviços públicos e a caracterização de unidades privadas que executem serviços de titularidade pública, uma vez que a dicotomia entre o dever servir e o dever impor recíprocos nesta relação apenas encontrará limite no pleno desenvolvimento de ambos os pólos. Objetivo que até o momento não tem expectativas de fim, considerando a eterna busca evolutiva dos envolvidos.

Como já observado, a participação da iniciativa privada na exploração dos serviços é feita mediante autorização, concessão ou permissão, nos termos do que dispõe o art. 21, XI e XII, da CF. Cabe às respectivas leis criadoras das agências reguladoras, entre outros aspectos, trazerem os direitos e deveres tanto ao Poder Público quanto aos usuários. Para o momento, interessa observar como o Estado atua na condição de efetivo regulador da prestação de serviço público, de forma geral. As empresas, como partícipes do ambiente privado, têm limitação própria desse regime para atuar. Entre- 
tanto, essa limitação é condicionada à tarefa pública que se propõe, fato que remonta sua natureza jurídica, quando vista na concretude e na eficácia de sua atividade precípua.

A respeito dessa propensa liberdade empresarial, condicionada ao mister público, Marcus Vinicius Corrêa Bittencourt (2006, p. 76) leciona que:

[...] a expressão "liberdade de empresa" consiste em um direito subjetivo que encontra limites no ordenamento jurídico, com fundamento no interesse da coletividade. $\mathrm{O}$ operador econômico, ao prestar materialmente um serviço qualificado como público pela ordem jurídica, recebe um condicionamento intenso por parte do Estado em relação à sua esfera de liberdade. Essa medida se faz presente, pelos interesses que estão em jogo, merecedores de especial proteção pelo Estado.

Para o autor (p. 76),

[...] não se trata de supressão do direito subjetivo à liberdade de empresa, mas um comprometimento maior por parte do particular para se atingir determinados resultados em prol da coletividade, cuja competência incumbe originalmente à Administração Pública.

Desse modo, estabelecidas as ideias sobre concessão e concessionária de serviço público, cabe agora - em síntese - a apresentação de alguns vetores voltados às concessionárias nas atividades públicas que exercem. Trata-se de exigências que devem ser implantadas, de forma geral, pelas agências, as quais - complementares aos princípios aplicáveis à adequada prestação do serviço público em tela - devem ser verificadas para o alcance da preservação dos básicos direi- tos do cidadão (usuário/consumidor), da forma que segue:

a) organizar e manter conselhos de usuários integrados por representantes de organizações das diversas classes de usuários e órgãos oficiais de defesa do consumidor, de caráter consultivo ${ }^{1}$ e voltados para orientação, análise e avaliação dos serviços e da qualidade do atendimento pela prestadora, bem como para formulação de sugestões e propostas de melhoria dos serviços;

b) garantir acessibilidade ao serviço e dar atendimento prioritário às pessoas portadoras de necessidades especiais, bem como manter centrais de atendimento para intermediação eficiente da comunicação direta com os cidadãos;

c) fornecer ao usuário a comparação do serviço de sua opção com o serviço básico que deve ser obrigatoriamente oferecido;

d) conceder, ao consumidor prejudicado, crédito relativo à interrupção do serviço prestado, proporcional ao prejuízo que a interrupção causou, tendo como base de cálculo o preço correspondente ao serviço que deveria ter sido disponibilizado;

e) promover a máxima orientação do usuário, com vistas a garantir o pleno conhecimento dos serviços a ele prestados. 


\section{Princípios constitucionais da administração pública expressos no caput do art.37 da CF/88}

Princípio da legalidade

Conforme determinação constitucional, o princípio da legalidade trata da obrigatória necessidade de adequação legal estrita quando da prestação de serviço público. O foco está concentrado, sob igual aspecto, no atendimento juridicamente regular do sistema socioeconômico, isto é, não se afasta da prestação do serviço público a preocupação dos efeitos que tais atividades causam no sistema.

$\mathrm{O}$ atendimento ao princípio da legalidade, por óbvio, deve ser compreendido de acordo com a ideia de hierarquização legislativa, de forma que o prestador de determinado serviço público atue estreitamente como regem os ditames constitucionais (prioritariamente), as leis infraconstitucionais e os atos normativos administrativos (e/ou regulatórios), nessa ordem.

A ideia principal da legalidade consubstancia-se na atuação conforme a lei, entretanto, tal princípio não pode ser visto tão somente sob o prisma da 'reserva de lei'. Mais que o atendimento à legalidade estrita, a atuação da prestação de serviço público deve procurar realizar os valores que conformam o direito. Conforme se destaca das lições de Pontes de Miranda (1973), a atuação da Administração Pública deve estar disposta nos trilhos da lei e do Direito. Contudo, quando houver dúvida ou receio entre o atendimento à expressão positivada (lei) ou aos seus valores alicerces (Direito), certamente o segundo deve preponderar, pois é insuscetível obrigação do sistema jurídico regulador zelar pelos seus valores básicos (direitos fundamentais), a ponto de assegurar o seu correto desenvolvimento e caminho rumo à preservação e constante fomento ao bem-estar daquele que lhe confere energia: o cidadão.

\section{Princípio da impessoalidade}

Conforme Jacques Chevallier (2003), há uma tendência de intensificação da luta contra as discriminações, seja na esfera política, jurisdicional e nos textos normativos. $\mathrm{O}$ princípio da não discriminação se retrata no conjunto de diversos princípios fundamentais estabelecidos na organização sociopolítica que sustentam o regime democrático.

Ao tema, depreende-se a estrita necessidade de verificação da concreta prestação universal do serviço público ${ }^{2}$ - de modo a não priorizar inadequadamente aqueles grupos ou regiões mais lucrativos aos concessionários (como os grandes centros urbanos). Isto é, trata-se da ideia de prestar o serviço público de forma a diminuir a inevitável desigualdade social que acompanha o estabelecimento de novas tecnologias e facilidades para a população. Primar pela prestação de serviço de forma igual aos usuários significa maior atenção aos que apresentam dificuldades ao seu acesso - sem deixar de manter o necessário desenvolvimento e a manutenção do serviço para todos.

A exigência de universalizar os serviços públicos apresenta-se como o maior dilema das empresas privadas, uma vez que encarece a sua produção e a implantação do 
sistema que viabiliza a adequada prestação do serviço público. Contudo, trata-se de imposição e condição do Estado, para que a concessionária possa - de forma legítima aferir todo o bônus decorrente do mercado em que está atuando.

A universalização da prestação do serviço público, bem como sua efetiva verificação são estritamente necessárias para demonstrar que o dever primário de bem prestar, bem prover, ainda pertence ao titular desse serviço, o Estado. O privado foi chamado para executar esses serviços pela razão de que detém, atualmente, aprimoradas condições para melhor servir. Nesse sentido, mais uma vez, ressalta-se a importância de um ambiente regulatório estável, firme em suas decisões, justo no exercício fiscalizatório e sancionatório e sempre voltado à preservação da sociedade.

Conforme Marcello Caetano (1999, p. 1079-1080),

[...] destinados ao público, os serviços públicos devem proporcionar as prestações, por igual, a todos os indivíduos que as solicitem. O princípio fundamental a observar na utilização dos serviços públicos é, pois, o da liberdade de acesso às suas prestações. Pode, porém, a lei condicionar essa liberdade exigindo certos requisitos ou o cumprimento de certas formalidades ou obrigações para ser possível obter as prestações do serviço. Nesse caso, tais condições terão de ser formuladas em termos gerais e impessoais de modo a garantir a igualdade de tratamento dos [usuários] (grifo nosso).

Isto é, para se atender ao princípio da igualdade, deve-se, por vezes, tratar o usuário de maneira desigual - na amplitude e nos limites racionais de suas verificadas dis- tinções - no sentido de conceder ao usuário de serviço público paridade de condições de usufruí-lo.

Na prática, aquele que reside, por exemplo, em uma região de difícil acesso à luz e não tem condições econômicas suficientes para retribuir proporcionalmente ao serviço posto à sua disposição, em nome da fundamental necessidade de exercício social do serviço que, por essência é público - voltado a todos -, deve o Estado subsidiar e o particular suportar o ônus de propagação da atividade estatal que exerce ao homem que por questões geográficas, sociais ou econômicas não tem a mesma capacidade de retribuição de outro que reside em um grande centro urbano e possui aprazíveis condições sociais e financeiras.

Do contrário, a prestação do serviço público nacional cairia na condição fria da análise econômica já expressada no item sobre direito e economia. Não se pode aceitar, destarte, a objetiva interpretação econômica do direito sem o necessário filtro social e da preservação da dignidade da pessoa humana, conforme proposto no presente estudo. De forma diversa, chegar-se-ia à inaceitável conclusão de que aquele que detém melhores condições geográficas, sociais ou econômicas tem o direito, por tais razões, de receber uma maior e melhor contraprestação das atividades estatais, fato que corrói todo o alicerce da República Democrática estampada para a nação.

\section{Princípio da moralidade}

Trata-se da ideia de não ocorrência de possibilidade de atuação disforme aos mínimos padrões de ato escorreito estabelecidos 
em uma sociedade. Apesar de certa carga de subjetividade que esse princípio contém, quando da verificação da adequação ao direito, do serviço público prestado, deve o intérprete observar se os valores do bem atuar mediante contraprestações justas e legítimas foram verificados pelas partes envolvidas.

Os valores que compõem o Princípio Constitucional da Moralidade da Administração Pública (art. 37, caput, CF/88), como ferramenta de verificação do controle, não só social, pode ser compreendido no sentido de se agir com probidade, com boa fé, com lealdade, com razoabilidade, com responsabilidade e conforme os valores de proporcionalidade administrativa.

\section{Princípio da publicidade}

Trata-se da necessária e ampla divulgação dos atos das empresas particulares, principalmente aqueles que tragam algum impacto econômico ao cidadão (usuário/ consumidor). Também, no sentido de viabilizar o controle dos atos das concessionárias perante os meios de controle democráticos institucionalmente constituídos.

Diretamente ligada à ideia de publicidade, a atuação transparente de tais empresas deve ser preocupação primordial de seus dirigentes e daqueles que exercem o controle (interno e externo) sobre elas. De igual maneira, a Administração Pública concede elementos para a efetivação de seu obrigatório - e constitucional - controle por entes externos por meio de promoção da maior transparência possível de suas atividades. Para tanto, é essencial que se utilizem os meios de publicidade atuais, como a internet (bem como meios escritos e radiofônicos), para que se atinja e se esclareça a população, sobre sua atuação, com a abrangência necessária para a eliminação de dúvidas e desconfianças sobre o seu exercício público (ou daqueles que lhe façam as vezes). Ideia essa que é importante para conceder previsibilidade, estabilidade, segurança e eficiência do atuar administrativo - pontos relevantes para promoção de um responsável desenvolvimento estatal.

\section{Princípio da Eficiência}

Cristiane Derani expressa a forma adequada de verificação da eficiência dos serviços públicos concedidos à execução do particular. Assim, leciona que:

[...] a performance dos serviços públicos não saberia se definir e se avaliar exclusivamente pela ótica das empresas do setor privado. Ela está em função do equilíbrio a atingir entre dois imperativos: respeitar as imposições financeiras e responder às necessidades dos cidadãos-usuários. Este equilíbrio não saberia estar fixado no abstrato e sua determinação incumbe aos tomadores de decisões políticas, levando em conta a situação da coletividade. O processo para otimizar a realização dos serviços públicos passa assim, em primeiro lugar, por uma avaliação correta das necessidades; em segundo lugar, pela determinação de objetivos e programas coerentes com as necessidades constatadas; em terceiro lugar, pela busca de uma qualidade das prestações, apropriada em relação a suas necessidades; enfim, pela busca de melhor produtividade e do menor custo no fornecimento das prestações (2002, p. 152-153, grifo do autor). 
Do princípio constitucional da eficiência da Administração Pública não se espera uma atuação perfeita, mas, sim, uma contínua busca de excelência em suas atividades. $\mathrm{O}$ cidadão que concede força para a Administração funcionar espera nada menos que qualidade proporcional ao empenho concedido quando financia o Estado - pelos tributos - e quando trabalha para auxiliar no bom funcionamento da máquina pública. Desse modo, a eficiência é o bem agir para bem atender o cidadão, sem pretensões de perfeição, mas com objetivos claros de desenvolvimento e metas sólidas, responsáveis, sindicáveis e que oportunizem a participação de todos nesse bem comum.

Assim apresentado, para atingir-se a adequada atuação administrativa não se pode deixar de lado o elemento da eficiência. Entretanto, como já exposto neste texto, é estritamente necessário que tal elemento não venha desacompanhado de sua indispensável adaptação constitucional dos valores sociais de sua expressão, pois é por meio desse que o Estado operacionaliza adequadamente seu maquinário para viabilizar os seus objetivos - com destaque aos sociais estabelecidos na Carta Maior.

Mas o que esperar da Administração, o eficiente ou o ótimo?

Segundo Amartya Sen (2000, p. 47-48),

[...] considera-se que um determinado estado social atingiu um ótimo de Pareto $^{3}$ se e somente se for impossível aumentar a utilidade de uma pessoa sem reduzir a utilidade de alguma outra pessoa. Esse é um tipo muito limitado de êxito e, em si mesmo, pode não garantir grande coisa. Um estado pode estar no ótimo de Pareto havendo algumas pessoas na miséria extrema e outras nadando no luxo, desde que os miseráveis não possam melhorar suas condiç̃oes sem reduzir o luxo dos ricos. Para o autor, a otimalidade de Pareto às vezes também é denominada "eficiência normativa". Essa expressão é apropriada de um ponto de vista, pois a otimalidade concerne exclusivamente à eficiência no espaço das utilidades, deixando de lado as considerações distributivas relativas à utilidade. Porém, em outro aspecto é inadequada, uma vez que todo o enfoque da análise neste caso continua sendo a utilidade, e esse é um legado da tradição utilitarista anterior. Obviamente, é possível introduzir outras considerações na avaliação do êxito das pessoas e, portanto, da sociedade. A otimalidade de Pareto capta os aspectos da eficiência apenas do cálculo baseado na utilidade (grifo do autor).

Como visto, a eficiência - demonstrada pela otimilidade de Pareto - vista apenas por esta ótica, torna-se vazia. Não presta para o alcance da resposta imposta pela Constituição. Assim, mister se faz a produção de sua filtragem, por meio dos valores do Direito, ${ }^{4}$ para que tenha serventia a esperada atividade da boa administração.

O raciocínio econômico puro ignora os valores de Justiça e Liberdade e, assim, quando o Direito precisa utilizar seus elementos para o alcance de seus fins, faz-se necessária a filtragem daquele raciocínio econômico, de acordo com tais valores, com o fito de que não prosperem conclusões simplesmente individualistas da análise jurídico-econômica proposta, fato que resultaria em frontal ofensa aos valores constitucionais legitimados no Estado nacional.

Nessa linha, Cristiane Derani (1996, p. 62) sustenta que 
[...] da mesma forma que a produção não é possível de ser observada e modificada sob aspectos inteira e puramente econômicos pois fatores culturais, históricos e naturais, ou seja, características específicas das relações que envolvem a sociedade, hão de ser observadas -, o direito econômico não deve ser visto como o direito da economia. A produção econômica não é isolada da produção da vida social.

Assim, firma-se a ideia de que a atuação estatal deve ser observada quando, para atingir adequadamente seus fins, os valores do Direito e os preceitos estruturantes da Economia estiverem voltados a proporcionar o constitucional objetivo de promoção e desenvolvimento do homem.

A eficiência, quando da prestação de serviço público, está intimamente ligada à "Continuidade do serviço público": a Lei Geral de Concessões de Serviços Públicos, no $\S 1^{\circ}$ de seu art. $6^{\circ}$, refere-se à continuidade do serviço público como uma das condições para a sua correta prestação conforme o direito, assim como aponta as hipóteses em que o concessionário pode paralisar ou interromper a execução do serviço licitamente, caso contrário, a empresa encontra-se sujeita a sanções, tais como: rescisão contratual e responsabilidade por perdas e danos. Nessa linha, a Lei Geral de Telecomunicações, em seu art. $79, \S 2^{\circ}$, determina aos concessionários:

Obrigações de continuidade são as que objetivam possibilitar aos usuários dos serviços fruição de forma ininterrupta, sem paralisações injustificadas, devendo os serviços estar à disposição dos usuários, em condições adequadas de uso.
Neste momento, oportuno é o debate sobre a possibilidade de interrupção da prestação de determinado serviço público, tendo em vista a inadimplência econômica do usuário. Segue o enfoque do STJ sobre a questão:

[...] a continuidade do serviço público assegurada pelo art. 22 do CDC não constitui princípio absoluto, mas garantia limitada pelas disposições da Lei 8.987/95, que, em nome justamente da preservação da continuidade e da qualidade da prestação dos serviços ao conjunto dos usuários, permite, em hipóteses entre as quais o inadimplemento, a suspensão no seu fornecimento (grifo do autor). ${ }^{5}$

Entretanto, também é possível encontrar posicionamentos contrários na mesma corte superior, que afirma que não resulta em se reconhecer como legítimo o ato administrativo praticado pela empresa concessionária fornecedora de energia e consistente na interrupção de seus serviços, em face de ausência de pagamento de fatura vencida, mas, sim na verificação de um bem essencial à população, constituindo-se serviço público indispensável, subordinado ao princípio da continuidade de sua prestação, torna-se impossível a sua interrupção. ${ }^{6}$

Como se depreende da leitura das exposições do STJ, existe um elo entre o critério de essencialidade do serviço público - inadimplemento de pagamento de tarifas, pelo usuário - e a possibilidade de não atendimento ao basilar princípio da continuidade de serviço público. Em conclusão do debate, é importante ressaltar que os serviços públicos são constitucionalmente indicados como de responsabilidade do Poder Público e, este, dentro da ideia da reserva do possível, deve utilizar-se de todos os meios necessários para sua manutenção. 
O ponto relevante dessa questão é o inafastável mister da concessionária em primar pela máxima possibilidade de constante prestação do serviço concedido, para que os cidadãos não sofram qualquer cerceamento de seus direitos, quando da atuação indireta do Estado.

Da mesma forma, o princípio da eficiência está conectado à ideia de "menor impacto econômico do usuário de serviço público": depreende-se desse princípio a ideia de que, seja qual for a política adotada pelo Estado, por intermédio de suas entidades reguladoras, ou pela atuação das concessionárias públicas - na busca de novas formas de obtenção de lucro - deve o respectivo cidadão usuário/consumidor receber o menor impacto econômico possível. Desse modo, sublinha-se o papel das instituições públicas e privadas voltadas ao controle de eventuais abusos realizados pelo Estado e pelas empresas concessionárias. Nesse cabo-de-guerra, o cidadão deve munir-se de elementos de força para, na sua condição vulnerável, receber de maneira proporcional e razoável os reflexos dos movimentos econômicos, de avanço tecnológico e de necessidade de manutenção do sistema, praticados pelos outros personagens já destacados.

Cabe enfatizar que a verificação do aludido princípio há de ser exercitada em todos os momentos da atuação dos citados personagens, tais como: (a) o estabelecimento do contrato de concessão; (b) termos de atualização de tarifas; (c) exigência de formas de contraprestação pelo serviço público prestado; (d) meios de tratamento de eventual inadimplência; e outros.
De maneira complementar, ainda no tocante à sua adequação operacional para implementação do efetivo atendimento ao primado dos direitos fundamentais (em que encontra seu eixo no princípio da dignidade da pessoa humana - art. $1^{\circ}$, III, CF/88), a prestação do respectivo serviço público possui a obrigatoriedade de acolhimento dos demais princípios do direito administrativo e do consumidor.

\section{Consideraçoes finais}

Constitui-se como a adequada prestação do serviço público - realização dos princípios constitucionais expressos no caput do art. 37 da CF/88, nessa atividade - aquela realizada conforme os valores exarados pelos direitos fundamentais do cidadão, pois, como afirma Jaime Rodriguez-Arana (2005), a promoção de direitos fundamentais não é algo que a Administração tenha de tolerar, mas bem promovê-los incansavelmente.

Quando, por exemplo, o concessionário obtém a delegação de prestar atividade estatal ao cidadão, os interesses e valores do regime público - notoriamente detentor de uma margem de atuação mais estrita e vinculada aos ditames normativos preconcebidos, em face do regime privado - preponderam, no momento do estabelecimento de sua relação com o destinatário (cidadão) dessa atuação do concessionário, tendo em vista as obrigações assumidas com o titular da atividade prestada indiretamente pelo particular (Estado).

Destarte, a partir da admissão do ônus de bem prestar e servir o serviço público, não há meio da empresa concessionária de tal 
serviço não aceitar a direta aplicabilidade e eficácia dos direitos fundamentais à sua atuação e condição de prestadora de serviço público.

Sobre essa assertiva, vale lembrar as lições de Ingo Wolfgang Sarlet:

No que diz com a eficácia dos direitos fundamentais propriamente dita, há que ressaltar o cunho eminentemente principiológico da norma contida no art. $5, \S 1^{\circ}$, da nossa Constituição, impondo aos órgãos estatais e aos particulares (ainda que não exatamente da mesma forma), que outorguem a máxima eficácia e efetividade aos direitos fundamentais, em favor dos quais (seja qual for a categoria a qual pertençam e consideradas as distinções traçadas) milita uma presunção de imediata aplicabilidade e plenitude eficacial.

[...] afinal de contas, como bem lembram Laurence Tribe e Michael Dorf, as normas da Constituição - e, no nosso entender, especialmente aquelas que versam sobre os princípios e direitos fundamentais - não devem ser tratadas como um espelho, no qual todos enxergam o que desejam ver (SARLET, 2005, p. 441-442).

\section{Abstract}

It serves as the adequate provision of public services - fulfillment of constitutional principles in the heading of article. 37 of CF / 88 in this activity - that performed according to the values formally drawn up for fundamental rights of the citizen. The idea of public service is not static, undergoes constant change depending on numerous factors such as the historical moment and the place in which it is given particular activity that demonstrates the existence of functio- nality to the community, justifying its implementation by the State, either directly or indirect. We intend to present the constitutional principles of public administration from the implementation of these in the course of providing the public service, directly or indirectly by the state and its delegatários.

Keywords: Public Administration. Public Service. Principles.

\section{Resumen}

Es la adecuada prestación de los servicios públicos - el cumplimiento de los principios constitucionales en el encabezamiento del artículo. 37 de CF / 88 en esta actividad - que realizó de acuerdo a los valores formalizados por los derechos fundamentales del ciudadano. La idea de servicio público no es estática, sufre un cambio constante que depende de numerosos factores, tales como el momento histórico y el lugar en el que se da la actividad particular que demuestra la existencia de funcionalidad a la comunidad, lo que justifica su aplicación por el Estado, ya sea directamente o indirecta. Tenemos la intención de presentar los principios constitucionales de la administración pública en la aplicación de estos en el curso de la prestación del servicio público, directa o indirectamente por el Estado y sus delegatários.

Palabras clave: Administración Pública. Servicio Público. Principios. 


\section{Notas}

1 Defende-se que tais conselhos deveriam - também - emitir pareceres vinculantes, uma vez que atuam na defesa do consumidor.

2 Exemplifica-se o respectivo princípio com a sua aplicação na prestação de serviço de telefonia. A Lei Geral de Telecomunicações assim expressa: “Art. 79. A agência regulará as obrigações de universalização e de continuidade atribuídas às prestadoras de serviço no regime público. $\S 1^{\circ}$ Obrigações de universalização são as que objetivam possibilitar o acesso de qualquer pessoa ou instituição de interesse público a serviço de telecomunicações, independentemente de sua localização e condição socioeconômica, bem como as destinadas a permitir a utilização das telecomunicações em serviços essenciais de interesse público".

3 Ótimo de Pareto é um conceito de economia desenvolvido pelo italiano Vilfredo Pareto. Uma situação econômica é ótima no sentido de Pareto se não for possível melhorar a situação, ou mais genericamente a utilidade, de um agente, sem degradar a situação ou utilidade de qualquer outro agente econômico. Numa estrutura ou modelo econômico podem coexistir diversos ótimos de Pareto. Um ótimo de Pareto não tem necessariamente um aspecto socialmente benéfico ou aceitável. Por exemplo, a concentração de rendimento ou recursos num único agente pode ser ótima no sentido de Pareto.

4 Principalmente: moral, justiça e liberdade.

5 STJ, 1. ${ }^{a}$ T., REsp 591692/RJ (2003/0162707-1), rel. Min. Teori Albino Zavascki, j. 03.08.2004, DJ 14.03.2005, p. 205.

6 STJ, 1. ${ }^{\text {a }}$ T., REsp 715074/RS (2005/0001684-1), rel. Min. José Delgado,- j. 03.03.2005, DJ 04.04.2005, p. 230.

\section{Referências}

BITTENCOURT, Marcus Vinicius Corrêa. Controle das concessões de serviço público. Belo Horizonte: Fórum, 2006.

CAETANO, Marcello. Manual de direito administrativo. Coimbra: Almedina, 1999.

CHEVALLIER, Jacques. Lutte contre les discriminations et État-providence. In: BORILLO, Daniel. Lutter contre les discriminations. La Découverte: Paris, 2003. p. 38-58.

. As novas fronteiras do serviço público.

Revista Interesse público. n. 51, p. 142-176. 2008.
COSTALDELLO, Angela Cassia. A propriedade privada, o urbanismo e as parcerias público-privadas: transformações e perspectivas. In: GUIMARÃES, Edgar (Coord.). Cenários do direito administrativo: estudos em homenagem ao Professor Romeu Felipe Bacellar Filho. Belo Horizonte: Fórum, 2004. p. 273-317.

DERANI, Cristiane. Privatização e serviços públicos: as ações do Estado na produção econômica. São Paulo: Max Limonad, 2002.

DERANI, Cristiane. Direito ambiental econômico. São Paulo: Max Limonad, 1996.

DI PIETRO, Maria Sylvia Zanella. Parcerias na administração pública: concessão, permissão, franquia, terceirização e outras formas. São Paulo: Atlas, 2008.

FREITAS, Juarez. O controle dos atos administrativos e os princípios fundamentais. São Paulo: Malheiros, 2004.

GROTTI, Dinorá Adelaide Musetti. O serviço público e a Constituição brasileira de 1988. São Paulo: Malheiros, 2003.

PONTES DE MIRANDA, F. C. Comentários à Constituição de 1967 com a Emenda n. 1 de 1969 t. III. São Paulo: RT, 1973.

ROCHA, Cármen Lúcia Antunes. Estudo sobre concessão e permissão de serviço público. São Paulo: Saraiva, 1996.

RIVERO, Jean. Direito administrativo. Coimbra: Almedina, 1981.

RODRIGUEZ-ARANA, Jaime. La vuelta al derecho administrativo (a vueltas con lo privado y lo publico). A \& C - Revista de Direito Administrativo e Constitucional, Belo Horizonte, ano 5, n. 20, p. 14, abr.-jun. 2005.

SARLET, Ingo Wolfgang. A eficácia dos direitos fundamentais. Porto Alegre: Livraria do Advogado, 2005.

SEN, Amartya. Desenvolvimento como liberdade. São Paulo: Cia. das Letras, 2000.

WEIL, Prosper. O direito administrativo. Coimbra: Almedina, 1977. 